dressing was ordered, and continued for the ensuing week :Chloride of lime, one drachm; lard, one ounce: to be applied three times a day, spread on lint, and kept constantly wetted with the chloride-of-soda lotion.

28th. - Some more bone removed. Glycerine to be applied with a camel's hair brush to the parts of the mouth that cannot be covered by the dressing. The bowels have not been opened since the 24th. An enema of castor-oil was given, followed by a cathartic enema, which brought away a quantity of dark æces.

29th. -The sloughing has nearly ceased; the wound looks well, but the edges are considerably everted.

30th. - Granulations tender and flabby; a bandage was passed round the neck so as to endeavour to make some distinction between the neck and chin.

July 4th. Alum lotion to be used instead of the chloride dressings. By careful straining on the surrounding parts, an incipient chin has been formed. Syringing out the sanious pus from the wound has given great relief.

From this time to the 18th, by the use of vulcanized india. rubber bands, (the French scentless ones were used, the face has become more shapely. An apparatus was worn, consisting of a hear-piece and chin-strap of linen, connected by the india. rubber bands. To-day he got up. He attempts to articulate, but cannot be distinctly understood. He derived considerable satisfaction by having a series of words and sentences written on a slate, so as to be able to point to what he wished to say.

12th. - Zinc dressings were applied over lint steeped in the alum lotion. A half-mask of gutta percha, lined with spongiopiline, was worn to keep up the dressings. He was allowed out in the garden.

13th to $19 \mathrm{th}$. - Extensive exfoliation of the alveolar process of the upper jaw and palate has taken place.

19 th to $22 \mathrm{nd}$. - The cavity of the wound is now considerably smaller. Can speak more plainly, though he never attempts labials.

August 4th. - He is rather feverish; the wound looks red and inflamed, with a tendency to erysipelas; talks very much better.

To have cathartic enema; his diet to be lowered.

11th. - The wound looks healthy again.

14th. - He is much improved now; he can talk tolerably plain, and gives the following account of himself:- "I can chew meat, talk, eat cake, plum-pudding, and kiss."

Sept. 25th. - He has cut two molars on the left side, and can make cnnsiderable grinding motion with them. The loss of saliva is very great on the right side; he speaks clearly. All the wound is quite healed.

From this time to the present date (Sept. 6th), he has continued to improve. His general health is excellent, and though obliged to have his chin tied up with a handkerchief, he manages to enjoy himself much as other children. The en. gravings show his present state, though when his mouth is shut the chasm does not appear so large; indeed, whilst resting his face on the right hand, I was able to have a photograph taken. for his relatives without showing any marked degree of de formity. I have great hopes, as he grows older, to make $\mathrm{i}^{\mathrm{t}}$ still less by a Taliacotian operation, and the aid of mechanical dentistry.

In the treatment of the case, the chlorine lotions and dressings were of the greatest advantage, whilst the bringing up of the loose skin of the face and neck, so as to form a new chin, was entirely due to the use of the vulcanized bands exerting a constant and equable pressure on all sides.

The medical treatment was conducted by my friend, Dr. Hurd, who occasionally gives him an aperient or saline dose, as there is now and then a tendency to erysipelatous inflammation, owing to the constant dribbling from the salivary fistula. have still hopes of relieving this as soon as the case is fit for further operative interference.

Wrington, 1860.

Italian Hospitals.-The spirit of charity is waking up at Naples. A great number of persons, especially ladies, visit the wounded, and all take something to relieve their wants. These attentions are so much the more prized that the Royal Government had left the administration of the bospitals, like all the rest, in a most deplorable condition. Volunteer sicknurses also abound. But it is not the same at Caserta. M. Kergomard, who has just arrived from that place tells me that the hospital of Caserta contains 300 wounded, and there are only five women, all persons of good family, to attend them. One only of these belongs to Caserta, and none to Naples. Naples Letter.
Af ilirror

OF THE PRACTICE OF

\section{METICINE AND SURGERY} IN THE

\section{HOSPITALS OF LONDON.}

Nulla est alia pro certo noscendi via, nisi quam plurimas et morborum te disectionum historias, tam aliorum proprias, collectas habere $\epsilon$ t inter se comparare.-Morgagni. De Sed. et Cirte. Worb., lib, 14. Proœmium.

\section{ST. BARTHOLOMEW'S HOSPITAL.}

CALCULUS IN THE BLADDER; LITHOTRITY-THE STONE CRUSHED IN FIVE SITTINGS, WITHOUT CHLORO-

FORM; GOOD RECOVERY.

(Under the care of Mr. SKEY.)

WITH the desire of fully illustrating the removal of stone from the bladder by the process of crushing, we place on record a few examples in which this proceeding was attended with complete success, in patients presenting some differences in the nature and general symptoms of their disease.

As contrasted with lithotomy, the operation of lithotrity is comparatively of very recent invention, and has been rather extensively employed of late years. Its present state of per. fection has been justly attributed to the labours of Civiale and Amussat in France, and of Brodie and Liston in this country. Many amongst the present generation of practitioners will remember when, but a few years back, it was the invariable custom to cut for stone-it was the operation then performed in our hospitals. Now a fair proportion of cases are submitted to crushing instead. Although the majority of cases, in public practice at least, are still subjected to lithotomy. this may depend, to some extent, upon the desire of exhibiting to pupils a more brilliant operation; for it must be acknowledged that, in point of display, the act of crushing a stone sinks into insignificance when contrasted with the performance of lithotomy? There is, perhaps, another reason why the latter is preferred, which is mentioned by Mr. Coulson in his standard work on the two operations: it is this-that "most surgeons perform lithotomy sufficiently well, yet when they come to lithotrity judgment and skill seem to have abandoned them. The dexterous lithotomist becomes a very indifferent lithotritist." This may explain the determined hostility which M. Velpeau has ever shown towards lithotrity, in consequence of the want of success which has attended his practice of the crushing operation. Of his first twelve patients thus treated, no less than three died; in four he had to abandon the operation, not being able to terminate it; and five were cured. On the other band, those who have, like ourselves, seen him perform the cutting operation, will admit the great skill he has always displayed, as well as the attendant success. Mr. Coulson states in his work, that Anussat, even so far back as 1835, declared that he found lithotrity applicable to three fourths of the calculous cases in his extensive practice.

We shall not, on the present occasion, enter into the subject of the suitable cases for crushing, nor of the indications for and against it, nor, again, into the statistics, which have yet to be worked out. There is this much to be said, however, in regard to the last, that most of the lithorrized cases are picked ones; whilst, on the contrary, lithotomy is performed on nearly all the other cases which present themselves.

Mr. Fergusson observes, in his " Practical Surgery," that, in the present stage of its bistory, we do not possess sufficiently authentic data by which to determine the safety of lithotrity as compared with lithotomy; but there need be no doubt of its applicability, and even superiority, in many instances. "In my own practice, I now tiud that I perform lithotrity more frequently and more successfully than in former years; but generally the cases occur in private practice. Ferhaps the reason of this is, that among those who do not seek hospital aid it is more generally known. that if the surgeon is applied 459 
to at an early date there is a better chance of the case proving suitable for this proceeding."-p. 788 .

In the following case, for the brief notes of which we are indebted to Mr. W. H. Farrington, house-surgeon to the hospital, the stone was about as large as a walnut, and altogether it was a most favourable one for tbis plan of treatment, which was followed on five occasions with complete success; that is, every remaining fragment was got rid of after the last crushing.

In March last, John B-, ayed thirty-five, was admitted into Abernethy ward, when the following history was obtained:- Up to twelve months ago he had good health, having suffered no pain nor inconvenience whatever in his urinary organs. From that time he dates his present symptoms, which have been gradually increasing. He now suffers from extremely painful and frequent micturition, followed by much straining. His urine, after standing, becomes thick and ropy. He has pain in the glans penis, and, in fact, all the symptoms of calculus, with chronic inflammation of the bladder. A sound being introduced, a calculus was readily detected, and was supposed to be about the size of an ordinary walnut.

March 31st. - Without the aid of chloroform, Mr. Skey introduced the lithotrite and crushed the calculus twice. After the operation the man passed several small pieces, and next day the vesical irritation had become much less.

On April 7th Mr. Skey repeated the operation, crushing the stone several times. Afterwards the patient voided a large quantity of fragments. The operation was again performed on the 14th, $17 \mathrm{th}$, and $21 \mathrm{st}$ of April, being followed each time by the passage of many fragments and relief to the inritable state of the bladder.

On April 28th the patient expressed himself as quite well, and able to hold and pass urine naturally. Urine quite clear. The sound does not detect the smallest piece of calculus.

October 6th. - Five months have elapsed, and no fresh symp. toms have appeared. There weve fivererushings within a montde. The calculus consisted of lithic. acid.

\section{UNIVERSITY COLLEGE HOSPITAI.}

OLD DISEASE OF THE BLADDER; NO URINE PASSED FOR YEARS EXCEPT BY THE CATHETER; CALCULUS ; LITHOTRTTY' SUCCEGSFUL.

(Under the care of Mr. HeNkY Thompson.)

THE subjoined case is remarkable and somewhat exceptional, on account of the successful application of lithotrity to a patient in whom there was total inability; to expel the fragments, owing to complete loss of power or "paralysis" of the bladder, a condition held by most, if not by all authors, to be a fatal objection to the employment of this operation. Every particle was removed by washing out the bladder with tepid water. The sittings were therefore made short, and only a swall quantity crushed at a time, to prevent undue embarrassment from lodging of débris at the neck of the viscus. The consequence was, that such blocking-up nover took place, and the result was perfectly successful.

J. B-_-, aged fifty-seven, a tall asd well-made man, first applied to Mr. Thompson as an ont-patient in June, 1858, with the following history:-He describes an attack of inflammation of the bladder, in 1845, as his finst experience of any disease of the urinary organs. He recovered from this after some time, and although suffering from some undue frequency in passing urine, had no subsequent attack until 1850 , when he was the subject of complete retention of urine, and the daily use of the eatheter was necessary afterwards for some time. A similar attack succeeded in the spring of 1853 , and annther, the most severe of all, in the autumn of the same year. For nearly three weeks all his urine was removed by the catheter; he lost considerable quinti ies of blood, and for three years possessed some, hut always imperfect, power of emptying bis bladder. In 1856 , he lost all control over his bladder, and colld evacuate no urine except by the entheter, which he now learned to pass for himself; and from this period until the present, with the exception of an interval of six weeks in 1856 , when he partially recovered the power, he has passed no urine whatever except by a gum catheter (No. 9), which he introdaces with ease six or seven times in the twenty-four hours.

Mr. Thompson examined him, and found no obstruction either in the urethra or at the neck of the bladder; a full-sized instrument slipped easily into the latter; and the prostate was 460 in no respect enlarged. The bladder is capacious; there is a moderate degree of chronic inflammation of its mucous membrane, as seen by the urine; otherwise this fluid, except being slightly alkaline, is bealthy; there is no albumen, nor are any renal casts seen. Every now and then, without apparent cause, he passes a very considerable quantity of blood; hæmorrhage continues for two or three days, and then gradually dis. appears. It does not seem to be produced by the catheter, which he nevertheless is continually passing, but occurs without any known cause.

Mr. Thompson sounded him carefully for stone, but could detect none. He follows an active employment, that of drawing an invalid chair, and takes a good deal of exercise daily in this way without much inconvenience, although he suffers considerable pain at times in the region of the bladder.

A number of remedies were tried-strychnia, steel, the infusions, \&c. From no internal medicine did he obtain any benefit for his complaint, although his general health improved. Some months afterwards he was sounded again, and again without success.

In June, 1859, he became the subject of one of his old severe aftacks of cystitis, without any obvious canse. Much pus and blood appeared in the urine, and it was necessary to pass the catheter ten or twelve times a day; the pains algo had increased in severity. On these symptoms subsiding, Mr. Thompson, strongly suspecting the presence of calculus, sounded him a third time on the 20 th of June, and on this occasion found one, apparently of moderate size. He was admitted to the hospital, and after watching his case a short time it was determined to crush the stone.

July 2na. - Having been an inmate for a few days, the first operation was fixed for to-day; but an unexpected attaok of hæmorrhage came on, no interference havino been attempted, except his own passing of the catheter, which he requires about eight times in the twenty-four hours, being wholly unable to pass: a drop without it.

10th. - All signs of blood having disappeared, and the general and local condition of the patient having much improved, $\mathbf{M r}$. Thompson introduced the lithotrite, and at once found, and speedily crushed, a stone of firm texture. No clilorofomm was administered; the patient exhibited no signs of pain. The débris adhering to the lithotrite was phosphatic. During the following three days phosphatic dëbris was passed by washing out the bladder.

13th. - No irritation having ensued, Mr. Thompson again gave the patient a sitting, the duration of which was abont two minutes. A litble fever ensued this time, but disappeared in a few hours.

19 th. - Third operation.

23rd. - Fourth operation. Much débris removed.

25th.-Fifth operation. A small fragment. remaining was crushed.

29th. - All the débris appeared to have come away. On sounding, nothing could be detected.

During the next week he was discharged. He had last all his pains; the urine was clear; the power of the bdadder remained the same as ever.

October 15th. - Called to report himself. He is perfectly free from all signs of stone; has passed no blood since he left the hospital, and the uriae is perfectly clear. He is better than he has been for many years, and is greatly improved in strength and appearance. He is actively following his old occupation, without any pain or inconvenience.

\section{SMALL CALCULUS IN THE BLADDER OF A BOT; LITHOTRITY} SUCCESSHUL, AT A SINGLE SITTING.

\section{(Under the care of Mr. Hengy Thovipson.)}

R. I_- aged ten, has been the subject of retention of urine frequently during the past month or two, with severe pain, and urine loaded with pus and mucus. The catheter has been frequently employed to relieve him. He was sent up from the country to be under Mr. Thompson's care on the 11th of last September. He lies with his knees drawn up on his abdomen, his left hand holding a very elongated prepuee, and his countenance exhibiting marks of considerable sufferingthe characteristie aspect of a young calculous patient. Urine flows from him almost constantly, and he rarely makes efforts to pass it, and then only with extreme pain; hence incontinence both night and day. The bladder has evidently become greatly distemded from his prolonged voluntary retention. On the night of the 13th complete retention came on, and $\mathbf{M r}$. Thompson was sent for. Passing an instrument, the calculus 